University of Texas Rio Grande Valley

ScholarWorks @ UTRGV

$12-2020$

\title{
Can caregivers trust information technology in the care of their patients? A systematic review
}

\author{
Alice Noblin \\ Barbara Hewitt \\ Murad Moqbel \\ University of Texas Rio Grande Valley, murad.moqbel@utrgv.edu \\ Scott Sittig \\ Lakesha Kinnerson
}

See next page for additional authors

Follow this and additional works at: https://scholarworks.utrgv.edu/is_fac

Part of the Business Commons, and the Health Information Technology Commons

\section{Recommended Citation}

Alice Noblin, Barbara Hewitt, Murad Moqbel, Scott Sittig, Lakesha Kinnerson \& Vera Rulon (2020) Can caregivers trust information technology in the care of their patients? A systematic review, Informatics for Health and Social Care, DOI: 10.1080/17538157.2020.1834399

This Article is brought to you for free and open access by the Robert C. Vackar College of Business \& Entrepreneurship at ScholarWorks @ UTRGV. It has been accepted for inclusion in Information Systems Faculty Publications and Presentations by an authorized administrator of ScholarWorks @ UTRGV. For more information, please contact justin.white@utrgv.edu,william.flores01@utrgv.edu. 


\section{Authors}

Alice Noblin, Barbara Hewitt, Murad Moqbel, Scott Sittig, Lakesha Kinnerson, and Vera Rulon 


\title{
Can caregivers trust health information technology in the care of their patients? A systematic review
}

\begin{abstract}
Background: The Health Insurance Portability and Accountability Act of 1996 (HIPAA) requires that healthcare providers allow patients to engage in their healthcare by allowing access to their health records. Often patients need informal caregivers including family members or others to help them with their care.
\end{abstract}

Aim: This paper explores whether trust is a key factor for informal caregivers' decision to use health information technologies (HIT) including electronic health records (EHR), patient portals, mobile apps, or personal connected devices to care for their patient.

Methods: Six reviewers conducted a comprehensive search of four literature databases using terms that pertained to a caregiver and trust to investigate the role trust plays when caregivers use HIT.

Results: While trust is a key factor for the use of HIT, it is not studied frequently since the researchers only identified ten articles that met the research question thresholds. Four main topics of trust surfaced including perceived confidentiality, perceived security, technological malfunction, and trustworthiness of the information.

Discussion: Trust is a critical factor for informal caregivers when using HIT to assist in the care of their patient (child, loved one, parent, or acquaintance). Based on the findings, it is clear that more research on the use of HIT by caregivers is needed.

Keywords: trust, informal caregiver, health information technologies, patient portal, electronic health record, caregivers 



\section{Introduction}

The Health Insurance Portability and Accountability Act of 1996 (HIPAA) gave patients access to their health records. To further support this effort, Meaningful Use, which was enacted as part of the 2009 Health Information Technology of Economic and Clinical Health Act (HITECH) rewarded certain providers who adopted electronic health records (EHR) with the goal of engaging the patients in their own health through patient portals. $(1,2)$ Consumer usage of health information technologies (HIT), such as EHRs, patient portals, mobile apps, wearable devices, implantable devices, or personal connected health devices, increased as a result of HITECH.(1) Patients are introduced to patient portals by physicians and other providers during episodes of medical care. One element that has impacted usage of HIT is patients' perceptions in terms of trust, including trust in the HIT and trust in the information provided by the HIT (e.g. correct results reporting).(3,4) Additionally, patient trust in technology is associated with trust in the care provider/practitioner and the type of interaction observed between the provider and the technology. Therefore, if a provider struggles with use of a technology, the patient may feel lack of trust of the provider or the technology.(5) Alternatively, if a provider uses a technology with ease, the patient will be reassured. For patients, trust requires a need to feel certain that the technology will not fail.(3) In other words, the HIT must be accurate, reliable and consistent.(4)

Patient portals are often used not only by patients but also by their informal caregivers (IC). Schulz and Tompkins (6) define IC as a family member that provides care to someone with whom they have a personal relationship and is typically unpaid. The National Center on Caregiving (7) defines family caregiver as "any relative, partner, friend or neighbor who has a significant personal relationship with, and provides a broad range of assistance for, an older person or an adult with a chronic or disabling condition." According to the United States Senate 
(8) Rosalyn Carter is credited for stating that three distinct groups of ICs exist: 1) children with chronic illness and disability who are typically cared for by young adult parents, 2) adult children with such conditions as mental illness who are cared for by middle-aged parents, and 3) older individuals who are cared for by their spouses or their middle-aged children. In this paper, IC is defined as, an unpaid individual who plays a critical role in the day-to-day management of healthcare processes and other routine needs of someone who cannot manage their own healthcare and day-to-day life, particularly the elderly or young. This individual could include either a relative, family member, care coordinator, care partner, parent, guardian, sibling, spouse, or friend. In other words, someone other than the patient themselves or their healthcare professional including physicians, physician assistants, nurses, nurse assistants as well as other care providers.

Pew Research estimated that approximately 93 million family members act as an IC in the United States, equivalent to $39 \%$ of the adult population.(9) ICs can better manage care processes using HIT such as patient portals. Providers must recognize that HIT might be utilized by older adults and other individuals who manage complex chronic diseases.(10)

ICs use HIT and online resources to care for loved ones but struggle with getting the right information at the right time.(11) According to Sterling,(11) ICs find themselves in a cycle where they are maintaining care while dealing with day-to-day challenges, managing a crisis (new problem), or transitioning to a new phase of recovery.(11) Information needs of these ICs differ depending upon the circumstances, but can include knowledge about medications, insurance, and social services among others. The availability of HIT to assist in managing dayto-day care can improve outcomes for patients but the caregiver must have adequate computer skills and willingness to use the HIT appropriately. 
Once the HIT is accessed, the IC acting as care coordinators, medical decision makers, medication administrators, and insurance navigators must be able to identify, track, manage, coordinate, connect, and understand available tools.(11) Challenges arise when searching for information and are compounded when the IC must first understand then apply relevant information in the care cycle. HIT often becomes another barrier for ICs who are often stressed by using patient portals.(12) A recommended action plan includes listening to the needs of ICs, educating them on HIT and other important resources, and training ICs on how to use the information gleaned from the HIT when performing medical tasks and navigating the next steps in their loved ones' care plan.(11)

ICs should receive training on the various types of HIT including web and mobile health applications that can be used to assist in the healthcare management of their patient.(13) Individuals under the age of 50 use HIT more readily and are more likely to access available HIT such as patient portals than those over 50.(9) However, pediatric portal utilization, usually accessed by ICs (parents or guardians) is generally low.(14) Most ICs (86\%) have internet access and 97\% indicate they are comfortable with computers.(9) While many ICs (57\%) are willing to use available HIT for caregiving, only $34 \%$ use it daily.,(15) This could be due to health literacy rates which can lead to an increased frequency of encountering barriers while using HIT.(16) In a recent study, the majority of ICs (72\%) stated that alerts for urgent healthcare needs was the primary motive identified for using HIT in their care plan activities.(15) For example, ICs for patients with epilepsy believe wearable monitors could identify triggers and provide warnings for imminent seizures.(17) Overall, reasons given for no or low use of available HIT include lack of awareness, cost, time required to learn new technologies, and belief that HIT will not improve care.(15) 
According to Ajzen and Fishbein (18), the theory of reasoned action (TRA) is based on behavioral intention as the primary predictor of actual behavior. Behavioral intention includes an individual's positive or negative attitude toward the behavior and social influences about the behavior. These influences are called "subjective norms" and refer to a person's belief that significant others have a favorable opinion of the behavior.

In the context of trust, we want to determine if the literature has shown that an IC's attitude about trust of HIT will impact their willingness to use the technology to care for their patient. The more favorable the attitude, the more likely it is that the caregiver will intend to perform the behavior, e.g., use the technology. Past research has included trust in technology as an attitudinal construct (19). Social pressures must also be considered for behavioral intentions. Therefore, the patient, as well as friends and family members may influence the caregiver's trust in HIT usage. Also, if a trusted provider is a strong advocate for the IC using HIT in the care of the patient, including training and supporting the IC in HIT usage, the intention to change behavior will be positively affected. Patients and ICs need to observe providers using HIT to improve their trust in the technology, which will also improve the patient's (and IC's) intention to use the technology.(5)

The goal of this research is to identify prior research on trust of the primary IC using HIT to gain information about and/or care instructions for the patient. The researchers' goal was to examine the literature to provide a meticulous summary of the published literature on trust of IC who utilize HIT. Thus, the research question is: "How is trust a key factor for family or ICs when engaging and using HIT to help with their caregiving activities?”

\section{Method}

Systematic reviews were originally developed to explore the trends in healthcare treatments in order to identify the best clinical practices or to thoroughly search the literature to identify what 
additional research should be completed. While systematic reviews were conducted without any robust methodology, three methodologies have emerged including the Cochrane Collaboration, the QUality Of Reporting Of Meta-analyses (QUOROM) and the Preferred Reporting Items for Systematic Reviews and Meta-Analyses (PRISMA) Method.(20) A group of six researchers with a background in health information management and health informatics explored the literature around IC's trust in HIT. The group was comprised of 4 researchers who have completed their $\mathrm{Ph} . \mathrm{D}$., an individual completing her dissertation, and an individual who had her master's degree. Over several meetings, the group identified a stream of research that they deemed extremely important. The research group narrowed the research focus to the importance of trust when an informal caregiver has to navigate a patient portal or use other HIT. The research group also utilized used the Preferred Reporting Items for Systematic Reviews and Meta-Analyses (PRISMA) method for this systematic review. $(21,22)$ Subsequently, the researchers identified literature databases that they used regularly to search for medical publications including ABI/Inform, CINAHL Plus, PubMed, and Science Direct. The search was limited to articles that were published between 2000 and 2019 since most healthcare organizations did not implement HIT until after 2000.(23)

\section{Inclusion/Elimination Criteria}

The researchers included studies that met the following criteria: 1) IC, 2) HIT, 3) mobile app, app, portal, wearable or internet of things' and 4) trust or acceptance of using an EHR (search terms are outlined in Table 1). The researchers included quantitative, qualitative, and mixed method studies in the analysis.

Articles that focused only on the healthcare professionals or the patient trust of the HIT were

eliminated. Articles that excluded attitude or trust toward the IC's EHR experience were removed. 
Exclusion criteria details were retrieved from the title, abstract, or the articles. To be considered, studies had to mention utilization of a HIT.

[Insert Table 1 near here]

\section{Results}

During the first round of reviews, four of the researchers entered the search algorithm into one of the four selected databases for this summative review. To eliminate articles in this round, the researchers reviewed the title from the original searches to ascertain if it appeared to be on subject as many of the articles originally selected by the search engines for the online databases were from the viewpoint of the provider (physician), another healthcare provider such as a nurse, or the patient. Each researcher compiled a list of articles that they felt were applicable to the research focus in Microsoft Excel including article title, authors names, journal titles, abstracts, and year of publication. Table 2 shows the total number of articles in the initial search from each database, the number of articles included in the table for the first elimination round and the number of articles that were included in our final review.

[Insert Table 2 near here]

Once the spreadsheets were combined into one spreadsheet, AN, MM, and BH reviewed all titles. The other researchers (LK, SS, and VR) reviewed the majority of the titles as well. All abstracts were reviewed by at least 4 researchers and articles that were not in agreement were reanalyzed. During the final round of reviews, $\mathrm{AN}$ and $\mathrm{BH}$ independently reviewed the full text of the articles and their results were compared for agreement. Figure 1 depicts process used to eliminate articles. $(21,22)$

[Insert Figure 1. Search Results] 
Through a thorough process of elimination, all but six of the 1,453 articles originally selected from the four online search databases were eliminated. Thus, the systematic review contained six articles from the original search and four located during the review of those articles, which revealed references to relevant papers. Five studies addressed utilization rates, six addressed caregiver satisfaction, three explored confidentiality issues, five examined security issues, and two focused on other trust issues. These results are shown in Table 3.

[Insert table 3 near here]

\section{HIT Types}

Several HIT types were identified during the review of the aforementioned articles. For example, some articles studied the attitude,(24) use, utility, impact,(25) as well as usability and value perceptions of caregivers toward the patient portal. $(26,27)$ Personal health records were also identified in several articles, including online immunization records,(28) electronic personal health records (EPHR),(29) and personal child health records.(30) Other HIT identified in the systematic review were Telehomecare,(31) electronic communication e-mail,(32) EHRs,(25, 33) wearable technology,(17) and mobile health applications.(13) The Internet of Things (IOT) was included in the search terms for the research; however, no articles related to caregivers were found. Table 4 summarizes the different HIT terms as defined by Oachs and Watters (34), along with examples.

[Insert Table 4 near here]

\section{Study Topics}

Four studies focused on patient portals, which may have included IC's access to the EHR and messaging with providers.(24-27) One study focused on telehomecare, using a web portal for 
home care nurses to enter data such as blood pressure, pulse, weight, prothrombin therapy, and electrocardiogram tracing, with interpretation by hospital-based physicians.(31) One study focused on an EHR created by parents of children with tracheotomies.(33) In addition three studies focused on pediatric electronic personal health records. $(27,29,30)$ The researchers included one study that focused on e-mail usage by parents because it looked at pediatric ICs' attitudes towards the use of electronic communication to identify requirements of implementing a patient portal with secure messaging.(32) Eight studies explored ICs (parents) of pediatric patients.(24, 25, 27-30, 32, 33) Two studies included a spouse/partner or other caregiver of an adult patient $(26,31)$. Three studies were international. $(25,30,31)$ And seven were based in the U.S.(24, 26-29, 32, 33) Sample size ranged from 8 to 229 with interviews and focus groups being the most common methods used for data collection. See Table 3 for details of the ten studies.

\section{Utilization of the HIT}

While exploring the viability of a patient portal, Bergman, Brown (24) found mixed results between teens and their parents who expressed conflicting concerns of confidentiality and access. A safety net hospital in San Francisco with plans to implement a patient portal also wanted to ascertain whether patients and ICs were interested in using the system.(26) A team of researchers in Denmark assessed the viewpoint of patients and their ICs using telehomecare technology and found that $80 \%$ of ICs used the internet daily and $80 \%$ were interested in using the Internet to manage health.(31) While the majority (81\%) of ICs indicated that they were comfortable with using the internet, only $25 \%$ reported knowledge of personal health records (PHR) when shown a new system for childhood cancer patients.(29) In another exploratory study 
with a system not yet in place, explored whether parents would access a PHR that included immunization information after seeing a demonstration of a prototype of the system.

The parents of children with a tracheotomy were regular HIT users but issues were encountered when sharing data with providers since the provider's EHR system did not interface with the IC's portal.(33) The majority (80.6\%) of parents who used an unsecure email portal to care for their chronically ill children admitted that they checked for messages only a few times a week.(32) When parents were asked to use the electronic Personal Child Health Record (eRedbook) in the United Kingdom for their children, they expressed concerns about costs for equipment and Internet service.(30) Two hundred fifteen parents who used the portal for their child three or more times in a year were identified as "portal users" in one study.(27) Another study that monitored usage of a new patient portal over 14-months after the portal was introduced considered ICs (parents) who accessed the portal an average of 2.5 times a month to be above average users.(25)

\section{Caregiver Satisfaction with the HIT}

Because of the variety of technologies and ICs involved in the studies; the reporting of satisfaction was inconsistent in the ten articles. Parents of teens shown a patient portal believed that the portal should be user friendly, but were concerned that their children might receive test results directly from the portal.(24) Parents of chronically ill children who used their e-mail accounts for communication were satisfied; however, the majority preferred not to get test results by e-mail.(32) Parents whose children have chronic illnesses found a portal to be easy to learn and use.(27) Parents with children at a rehabilitation hospital mentioned easy access to information and appointments, which was viewed as a time saver. While parents of children with tracheotomies were satisfied with the ability to input data, the ability to share the data with 
providers was not satisfactory.(33) The safety net population was shown pictures of screenshots for various portions of the portal and ICs voiced strong interest in being able to access the portal to assist with health care management of the patient.(25) As with the teen portal, the pediatric immunization record was also not in use yet, but parents were impressed by the prototype of the PHR provided in visual materials.(28)

\section{Perceived confidentiality issues with the HIT (Trust issue \#1)}

Confidentiality was the topic of concern in four of the studies. Teens and parents were concerned about confidentiality between each other. Teens were worried about information being shared with their ICs, the ICs were concerned that they wouldn't be made aware of certain issues involving their children.(24) Most parents of chronically ill children were confident in the portal with only $2 \%$ expressing concern about confidentiality of information.(27) Confidentiality was also mentioned in the Canadian study where parents were concerned about the scope of confidentiality.(25) Immigrant parents were concerned about confidentiality of immunization records and how their children's immigration status might be impacted by sharing of information.(28)

\section{Perceived security issues with the HIT (Trust issue \#2)}

Security was mentioned in five of the studies. Parents in an urban pediatric primary care clinic who were African American and in lower socioeconomic groups were more likely to have concerns about security with e-mail.(32) Parents of childhood cancer patients were concerned about data security, particularly in terms of insurance companies having access to information and denying coverage in the future.(29) These parents mentioned "hackers" as a concern,(35) as did $58 \%$ of parents in the urban pediatric primary care clinic who used their own e-mail for communication with providers.(32) ICs of adults in a safety net system (providing care to low- 
income, uninsured and vulnerable populations) mentioned familiarity with security breaches and a distrust of potential security measures based on their experiences.(26) Parents using the eRedBook mentioned data protection as a factor that would hinder them from using the personal health record for their child.(30)

\section{Other trust issues}

Use of a telehomecare system as a part of home hospitalization for heart failure and arrhythmia patients had mixed results from partners in the home.(31) Once the patient was discharged, the extensive electronic monitoring required in the home was stressful to spouses and/or partners with the technological malfunctions causing anxiety.(31) Patients are not as impacted/stressed by the actual malfunctions but were impacted by the ICs reactions. ICs expressed lack of confidence in the monitoring system.

Parents whose children have tracheotomies created an electronic reporting system to share information with the physicians. The parents were distrustful about the ability to share information bidirectionally.(33) This resulted in disorganized tracheotomy care and inconsistent data reporting, which impacted ventilator settings and other care plans. Parents were distrustful

of the information being shared, being unsure if the physician was receiving the information and feeling uncomfortable with providing some of the information. Despite this concern, $30 \%$ of the studies described improved communication between the caregiver and provider through emessaging.(25-27)

\section{Discussion}

These ten studies contribute to a better understanding of how ICs view HIT in terms of trust. In addition to privacy and security, trust was also mentioned in terms of equipment functioning and 
information sharing with providers. For example, complete sharing of accurate information by parents about tracheotomy patients impacts ventilator settings and ensures comprehensive care delivery.(33) Diabetes care, seizure monitoring, and fall detection provide additional examples of medical conditions where ICs benefit from trustworthy information provided by HIT for patient care. $(15,17,36,37)$

Wearable technology allows the patient and provider to communicate via the internet through an interconnection known as the Internet of Things (IoT).(37) This new technology also raises concerns regarding privacy maintained during short and long term communications.(38) In addition, an IC's ability to monitor wearables will alleviate anxiety about constantly monitoring their relative.(17)

The majority of the studies the researchers identified focused on parents or ICs of pediatric patients $(80 \%)$, and protection of the child's information was the most important topic in the studies. Since ICs of pediatric patients needs of information vary over time, they often struggle with getting necessary information at the right time.(11) The added layer of protecting information is noted as a barrier for some ICs in adopting the use of HIT.(39) ICs of senior citizens must also be vigilant in protecting personal health data of vulnerable relatives who may be targeted for medical identity theft.(13)

Many ICs expressed concerns that these HIT would be costly, would not solve any issues to improve care, or would take too much time to learn.(39) While the majority (70\%) of the parents of pediatric patients who participated in a demonstration of a patient portal planned to use the system again,(40) actual daily or weekly usage was reported as low, in the 2-10\% range, in longitudinal research.(27) 
Several of the studies (40\%) that we selected focused on the ICs expectation of the HIT. Only one study required a continued use of the HIT for two months and then they repeated the assessment after that time. This was a long-term study with an average use of the electronic system being nine months. The children were in a pediatric rehabilitation hospital and data was collected at numerous points, including capture of portal logins.(25) Educating ICs in the use of portals is an important step in an action plan to engage ICs in the care of a loved one.(10, 11,36) When getting started, the providers office may need to have designated staff available to answer simple questions about information on the portal.(10) The longer length of stay at the rehab hospital was helpful for educating and training ICs in portal usage over time.(25)

The most common HIT was a patient portal or a personal health record. Parents report information about vital signs, medications and daily schedules are most important.(41) A concern is inability to understand information, but health literacy wasn't measured in $90 \%$ of the studies included in this research and education level was not collected in $80 \%$ of the studies. Another challenge to the IC was understanding and using relevant information in a timely manner when caring for vulnerable patients. $(11,36)$ To better understand the results, the ICs needed explanation of diagnoses and test data.(41) ICs also need support from providers when questions arise about portal usage, including verifying and updating information.(10)

\section{Conclusions}

The purpose of this systematic review study was to investigate whether trust is a key factor for family and other ICs in engaging and using HIT to help with their caregiving activities. The Theory of Reasoned Action provided a framework for a caregiver's willingness to use HIT based on their attitude toward trust in the technology with input from significant others. The results indicated that trust is a factor for use of HIT. There are four main topics that surfaced in the 
systematic literature review when it comes to trust in using HIT by the primary IC in support of daily activities. The first topic relates to perceived confidentiality issues with the HIT use. The second topic pertains to perceived security issues with the HIT use. The third topic focused on technological malfunction issues with the HIT use, and the final topic was existence of trustworthy information as opposed to misinformation.

HIT developers, policy makers, and healthcare providers who are interested in utilizing HIT for ICs need to be aware that trust is a critical factor necessary to optimize HIT benefits/affordances. Not only is it important to emphasize the benefits of the use of HIT by ICs, but also it is imperative to identify and reduce the trust concerns that might impede the use of HIT. This study identified confidentiality, security, malfunctions, and trust in validity of the data being shared as important. Examining the trust issues helps identify mechanisms to reduce trust concerns. One way to reduce the trust concerns of HIT use is to get testimonies from healthcare professionals, patients, and other ICs that the HIT is trustworthy and delivers as promised. Further, reducing trust concerns will require further exploration of the topics (confidentiality, security, malfunctions, and trust in validity of the data) to target underlying causes. HIT developers, policy makers, and managers must be aware that trust is a critical factor necessary to ensure these ICs optimize their usage of patient healthcare systems. As Roslyn Carter reminds us, ICs can be young adult parents, adult children who take care of parents, and older adults who care for spouses and/or their middle-aged children. Awareness of HIT and trust in the valuable tools available for caregiving activities falls to all healthcare workers to ensure that the maximum value can be extracted from the constant advancements.

Meanwhile, several gaps in research on HIT use by ICs were revealed in this systematic review. First, based on the findings, additional studies to explore the use of HIT by ICs are 
needed. Second, research should also seek to understand what drives trust and the factors that predict the caregiver's perception of confidentiality, security, malfunctions (perceived and actual), and trustworthiness of the information in order to improve HIT adoption and sustain use. In conclusion, additional research is needed to identify the underlying causes of trust concerns to target solutions for lack of adoption of viable technologies that support caregiving actions. Specifically, focus should be on trustworthiness of the information shared via technologies that support caregiving activities.

Further evaluation of telemedicine, now referred to as telehealth, will also be required. According to the American Telehealth Association (42), telehealth now encompasses a much broader array of services and technologies that can include artificial intelligence, virtual reality and behavioral economics, that can transform the way health and care are delivered. With increased use of telemedicine by providers, patients, and caregivers due to the COVID-19 pandemic, issues of trust in video conferencing, appointments, and other forms of synchronous communication will be important to understand.

\section{Limitations}

The researchers identified four limitations in the research. First, it was difficult to define and identify all search terms that capture trust. We engaged the services of a librarian familiar with health HIT research and used a combination of terms to be as inclusive of the literature as possible. Though the number of ICs is large, the lack of research examining their use of HIT provides an additional challenge. Another limitation is that we searched four databases and in doing so may have missed some potential articles. However, ABI/Inform was used in our databases, which is very inclusive of other databases. 


\section{Competing interests}

None.

\section{Acknowledgements}

The authors would like to thank the University of Central Florida library staff for their help in guiding the authors in the search strategy and performing the database search.

\section{References}

1. Hsiao C-J, Jha AK, King J, Patel V, Furukawa MF, Mostashari F. Office-based physicians are responding to incentives and assistance by adopting and using electronic health records. Health Affairs. 2013;32(8):1470-7.

2. Blumenthal D, Tavenner M. The "meaningful use" regulation for electronic health records. New England Journal of Medicine. 2010;363(6):501-4.

3. Montague EN, Winchester III WW, Kleiner BM. Trust in medical technology by patients and healthcare providers in obstetric work systems. Behaviour \& information technology. 2010;29(5):54154.

4. Qiao Y, Asan O, Montague E. Factors associated with patient trust in electronic health records used in primary care settings. Health Policy and Technology. 2015;4(4):357-63.

5. Montague E, Asan O. Trust in technology-mediated collaborative health encounters: Constructing trust in passive user interactions with technologies. Ergonomics. 2012;55(7):752-61.

6. Schulz R, Tompkins CA, editors. Informal caregivers in the United States: prevalence, caregiver characteristics, and ability to provide care. The role of human factors in home health care: Workshop summary; 2010: National Academies Press (US).

7. National Center on Caregiving. Definitions San Francisco, CA2014 [Available from: https://www.caregiver.org/definitions-0.

8. EVERYDAY HEROES: FAMILY CAREGIVERS FACE INCREASING CHALLENGES IN AN AGING NATION: Hearing before the SPECIAL COMMITTEE ON AGINGUNITED STATES SENATE, 151 Sess. (September 10, 1998).

9. Fox S, Duggan M, Purcell K. Family caregivers are wired for health. Washington, DC: Pew Research Center's Internet \& American Life Project 2013.

10. Irizarry T, Shoemake J, Nilsen ML, Czaja S, Beach S, Dabbs AD. Patient portals as a tool for health care engagement: a mixed-method study of older adults with varying levels of health literacy and prior patient portal use. Journal of medical Internet research. 2017;19(3):e99.

11. Sterling M. What Family Caregivers Need from Health IT and the Healthcare System to be Effective Health Managers. 2015. 
12. Hu C, Kung S, Rummans TA, Clark MM, Lapid MI. Reducing caregiver stress with internet-based interventions: a systematic review of open-label and randomized controlled trials. Journal of the American Medical Informatics Association. 2014;22(e1):e194-e209.

13. Warpenius $E$, Alasaarela E, Sorvoja H, Kinnunen M. A mobile user-interface for elderly care from the perspective of relatives. Informatics for Health and Social Care. 2015;40(2):113-24.

14. Bush RA, Connelly CD, Fuller M, Pérez A. Implementation of the integrated electronic patient portal in the pediatric population: a systematic review. Telemedicine and e-Health. 2016;22(2):144-52.

15. AARP. Caregivers \& Technology: What They Want and Need. Project Catalyst Research Studies2016.

16. Tieu L, Schillinger D, Sarkar U, Hoskote M, Hahn KJ, Ratanawongsa N, et al. Online patient websites for electronic health record access among vulnerable populations: portals to nowhere? Journal of the American Medical Informatics Association. 2017;24(e1):e47-e54.

17. Bruno E, Simblett S, Lang A, Biondi A, Odoi C, Schulze-Bonhage A, et al. Wearable technology in epilepsy: The views of patients, caregivers, and healthcare professionals. Epilepsy \& Behavior. 2018;85:141-9.

18. Ajzen I, Fishbein M. Attitudes and normative beliefs as factors influencing behavioral intentions. Journal of Personality and Social Psychology. 1972;21(1):1-9.

19. Chuchinprakarn S. Application of the theory of reasoned action to on-line shopping. Knowledge Center E-paper Bangkok University. 2005:1-7.

20. Moher D, Liberati A, Tetzlaff J, Altman DG. Preferred reporting items for systematic reviews and meta-analyses: the PRISMA statement. Int J Surg. 2010;8(5):336-41.

21. Moher D, Liberati A, Tetzlaff J, Altman DG. Preferred reporting items for systematic reviews and meta-analyses: the PRISMA statement. Annals of internal medicine. 2009;151(4):264-9.

22. Moher D, Shamseer L, Clarke M, Ghersi D, Liberati A, Petticrew M, et al. Preferred reporting items for systematic review and meta-analysis protocols (PRISMA-P) 2015 statement. Systematic reviews. 2015;4(1):1.

23. Henry J, Pylypchuk Y, Searcy T, Patel V. Adoption of electronic health record systems among US non-federal acute care hospitals: 2008-2015. ONC data brief2016. p. 1-9.

24. Bergman DA, Brown NL, Wilson S. Teen use of a patient portal: a qualitative study of parent and teen attitudes. Perspectives in Health Information Management/AHIMA, American Health Information Management Association. 2008;5(13).

25. King G, Maxwell J, Karmali A, Hagens S, Pinto M, Williams L, et al. Connecting Families to Their Health Record and Care Team: The Use, Utility, and Impact of a Client/Family Health Portal at a Children's Rehabilitation Hospital. Journal of medical Internet research. 2017;19(4).

26. Tieu L, Sarkar U, Schillinger D, Ralston JD, Ratanawongsa N, Pasick R, et al. Barriers and facilitators to online portal use among patients and caregivers in a safety net health care system: a qualitative study. Journal of medical Internet research. 2015;17(12).

27. Byczkowski TL, Munafo JK, Britto MT. Family perceptions of the usability and value of chronic disease web-based patient portals. Health informatics journal. 2014;20(2):151-62.

28. Kitayama K, Stockwell MS, Vawdrey DK, Peña O, Catallozzi M. Parent perspectives on the design of a personal online pediatric immunization record. Clinical pediatrics. 2014;53(3):238-42.

29. Sharp LK, Carvalho P, Southward M, Schmidt ML, Jabine LN, Stolley MR, et al. Electronic personal health records for childhood cancer survivors: an exploratory study. Journal of adolescent and young adult oncology. 2014;3(3):117-22.

30. O'Connor S, Devlin AM, McGee-Lennon M, Bouamrane M-M, O'Donnell CA, Mair FS. Factors affecting participation in the eRedBook: a personal child health record. Nursing Informatics.

2016;225):971-2. 
31. Dinesen B, Nøhr C, Andersen SK, Sejersen H, Toft E. Under surveillance, yet looked after: telehomecare as viewed by patients and their spouse/partners. European Journal of Cardiovascular Nursing. 2008;7(3):239-46.

32. Dudas RA, Pumilia JN, Crocetti M. Pediatric caregiver attitudes and technologic readiness toward electronic follow-up communication in an urban community emergency department. TELEMEDICINE and e-HEALTH. 2013;19(6):493-6.

33. Berry JG, Goldmann DA, MandI KD, Putney H, Helm D, O'Brien J, et al. Health information management and perceptions of the quality of care for children with tracheotomy: A qualitative study. BMC health services research. 2011;11(1):117.

34. Oachs P, Watters A. Health information management: Concepts, principles, and practice. 6th ed. Chicago, IL: AHIMA Press; 2020.

35. Abrams K, Carlon S, Haugen MB, Mancilla D, McElroy K, Millen M, et al. HIM Reimagined Outlines Bold New Future for HIM Profession. Journal of AHIMA. 2017;88(6):22-5.

36. Mayberry LS, Kripalani S, Rothman RL, Osborn CY. Bridging the digital divide in diabetes: family support and implications for health literacy. Diabetes technology \& therapeutics. 2011;13(10):1005-12.

37. Panicker NV, Kumar S, editors. Design of a telemonitoring system for detecting falls of the elderly. 2015 International Conference on Green Computing and Internet of Things (ICGCloT); 2015: IEEE.

38. De Backere F, Bonte P, Verstichel S, Ongenae F, De Turck F. Sharing health data in Belgium: A home care case study using the Vitalink platform. Informatics for Health and Social Care. 2018;43(1):5672.

39. National Alliance for Caregiving. e-Connected family caregiver: bringing caregiving into the 21st century. National Alliance for Caregiving Bethesda, MD; 2011.

40. Ahlers-Schmidt CR, Nguyen M. Parent intention to use a patient portal as related to their children following a facilitated demonstration. TELEMEDICINE and e-HEALTH. 2013;19(12):979-81.

41. Kelly MM, Hoonakker PL, Dean SM. Using an inpatient portal to engage families in pediatric hospital care. Journal of the American Medical Informatics Association. 2016;24(1):153-61.

42. American Telehealth Association. Telehealth Basics 2020 [Available from:

https://www.americantelemed.org/resource/why-telemedicine/.

43. Baker SB, Xiang W, Atkinson I. Internet of things for smart healthcare: Technologies, challenges, and opportunities. IEEE Access. 2017;5:26521-44.

44. Joe J, Hall A, Chi N-C, Thompson H, Demiris G. IT-based wellness tools for older adults: Design concepts and feedback. Informatics for Health and Social Care. 2018;43(2):142-58.

Table 1. Search Terms

\begin{tabular}{|l|l|}
\hline Term & Connector \\
\hline $\begin{array}{l}\text { caregiver* OR famil* OR family member* OR relative* OR "care } \\
\text { coordinator" OR "care partner" OR parent* OR sibling* OR spouse }\end{array}$ & And \\
\hline $\begin{array}{l}\text { ("electronic health records" OR "EHR" OR "electronic medical record" } \\
\text { OR "EMR" OR "personal health record" OR "PHR") }\end{array}$ & And \\
\hline $\begin{array}{l}\text { ("mobile app*" OR "app*" OR "portal*" OR "wearable*" OR "internet } \\
\text { of thing*" OR "IOT") }\end{array}$ & And \\
\hline
\end{tabular}


(attitudes OR perceptions OR perspectives OR feelings OR confidence

OR trust OR acceptance OR adoption)

Table 2. Yield from Online Databases

\begin{tabular}{|l|l|l|l|l|}
\hline Search Engine & $\begin{array}{l}\text { Number of } \\
\text { articles in initial } \\
\text { search }\end{array}$ & $\begin{array}{l}\text { Number of } \\
\text { articles included } \\
\text { in preliminary } \\
\text { table }\end{array}$ & $\begin{array}{l}\text { Number of } \\
\text { articles } \\
\text { included in } \\
\text { deeper review }\end{array}$ & $\begin{array}{l}\text { Number of } \\
\text { articles that were } \\
\text { kept for } \\
\text { summative review }\end{array}$ \\
\hline ABI/Inform & 915 & 5 & 0 & 0 \\
\hline Cinahl & 239 & 18 & 5 & 4 \\
\hline PubMed & 267 & 23 & 3 & 2 \\
\hline Science Direct & 32 & 32 & 7 & 0 \\
\hline Total & 1,453 & 78 & 15 & 6 \\
\hline
\end{tabular}

Table 3. Summary of Articles

\begin{tabular}{|c|c|c|c|c|c|c|c|c|}
\hline$\stackrel{\varpi}{\circlearrowright}$ & 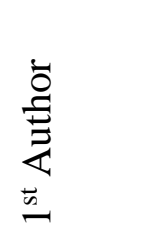 & 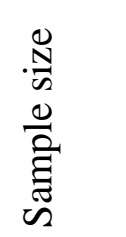 & $\underset{\Xi}{\stackrel{\Xi}{\Xi}}$ & : & 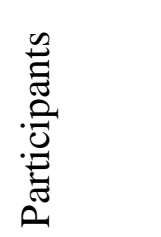 & 正 & $\begin{array}{l}\mathscr{\Xi} \\
\stackrel{\Xi}{\Xi} \\
\tilde{\Xi} \\
\sum\end{array}$ & 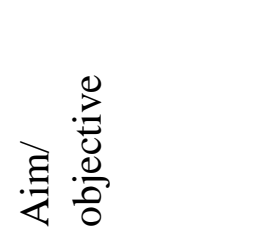 \\
\hline 2008 & Bergman & $\begin{array}{l}28 \\
\text { teens, } \\
23 \\
\text { parent } \\
\text { s }\end{array}$ & USA & $\mathrm{L}$ & $\begin{array}{l}\text { Teens \& } \\
\text { parents }\end{array}$ & $\begin{array}{l}\text { Patient } \\
\text { portal, } \\
\text { secure } \\
\text { messaging, } \\
\text { results } \\
\text { reporting }\end{array}$ & $\begin{array}{l}\text { Focus } \\
\text { groups, } \\
\text { online } \\
\text { bulletin } \\
\text { boards }\end{array}$ & $\begin{array}{l}\text { Ascertain } \\
\text { attitudes of } \\
\text { teens and } \\
\text { parents toward } \\
\text { use of portal }\end{array}$ \\
\hline 2008 & Dinesen & 8 & $\begin{array}{l}\text { Denmar } \\
\mathrm{k}\end{array}$ & $\mathrm{L}$ & $\begin{array}{l}\text { Patients } \\
>18 \\
\text { years \& } \\
\text { spouse/ } \\
\text { partner }\end{array}$ & $\begin{array}{l}\text { Telehomeca } \\
\text { re }\end{array}$ & $\begin{array}{l}\text { Electronic } \\
\text { records, } \\
\text { observatio } \\
\mathrm{n}, \\
\text { interviews }\end{array}$ & $\begin{array}{l}\text { Understand } \\
\text { experiences and } \\
\text { attitudes of } \\
\text { patients and } \\
\text { caregivers } \\
\text { toward } \\
\text { telehomecare } \\
\text { HIT }\end{array}$ \\
\hline 2011 & Berry & 8 & USA & $\mathrm{L}$ & Parents & $\begin{array}{l}\text { Electronic } \\
\text { health } \\
\text { record }\end{array}$ & Interviews & $\begin{array}{l}\text { Investigate } \\
\text { perceptions and } \\
\text { experiences of } \\
\text { parents with } \\
\text { health } \\
\text { information \& }\end{array}$ \\
\hline
\end{tabular}




\begin{tabular}{|c|c|c|c|c|c|c|c|c|}
\hline & & & & & & & & $\begin{array}{l}\text { care plan } \\
\text { development/co } \\
\text { ordination for } \\
\text { children with } \\
\text { tracheotomy }\end{array}$ \\
\hline 2013 & Dudas & 229 & USA & $\mathrm{N}$ & $\begin{array}{l}\text { Caregiver } \\
\mathrm{s}\end{array}$ & e-mail & Interviews & $\begin{array}{l}\text { Assess pediatric } \\
\text { caregiver } \\
\text { attitudes toward } \\
\text { use of electronic } \\
\text { communication } \\
\text { modalities in } \\
\text { urban clinic }\end{array}$ \\
\hline 2014 & Byczkowski & 215 & USA & $\mathrm{N}$ & Parents & $\begin{array}{l}\text { Patient } \\
\text { portal }\end{array}$ & $\begin{array}{l}\text { Telephone } \\
\text { survey }\end{array}$ & $\begin{array}{l}\text { Understand } \\
\text { parent } \\
\text { perceptions of } \\
\text { usability \& } \\
\text { value of portals } \\
\text { for children with } \\
\text { chronic illness }\end{array}$ \\
\hline 2014 & Kitayama & 29 & USA & $\mathrm{L}$ & Parents & $\begin{array}{l}\text { Online } \\
\text { immunizatio } \\
\mathrm{n} \text { records }\end{array}$ & $\begin{array}{l}\text { Focus } \\
\text { groups }\end{array}$ & $\begin{array}{l}\text { Examine desired } \\
\text { characteristics } \\
\text { of online } \\
\text { immunization } \\
\text { record for low- } \\
\text { income Latino } \\
\text { parents }\end{array}$ \\
\hline 2014 & Sharp & 11 & USA & $\mathrm{L}$ & Parents & $\begin{array}{l}\text { Electronic } \\
\text { personal } \\
\text { health } \\
\text { record } \\
\text { (EPHR) }\end{array}$ & Interviews & $\begin{array}{l}\text { Explore } \\
\text { knowledge, } \\
\text { interest, and } \\
\text { attitudes of } \\
\text { patients \& } \\
\text { caregivers } \\
\text { towards EPHRs }\end{array}$ \\
\hline 2015 & Tieu & 16 & USA & $\mathrm{L}$ & $\begin{array}{l}\text { Patients } \\
\& \\
\text { caregiver } \\
\text { s }\end{array}$ & $\begin{array}{l}\text { Online } \\
\text { patient } \\
\text { portal }\end{array}$ & $\begin{array}{l}\text { Semi- } \\
\text { structured } \\
\text { in-depth } \\
\text { interviews }\end{array}$ & $\begin{array}{l}\text { Explore patient } \\
\& \text { caregiver } \\
\text { perspectives on } \\
\text { portal use before } \\
\text { implementation } \\
\text { at a safety net } \\
\text { hospital }\end{array}$ \\
\hline 2016 & O'Connor & 12 & England & $\mathrm{L}$ & Parents & $\begin{array}{l}\text { eRedbook, } \\
\text { personal }\end{array}$ & $\begin{array}{l}\text { Qualitative } \\
\text { explorator }\end{array}$ & $\begin{array}{l}\text { Examine factors } \\
\text { that hindered } \\
\text { parent }\end{array}$ \\
\hline
\end{tabular}




\begin{tabular}{|l|l|l|l|l|l|l|l|l|}
\hline & & & & & $\begin{array}{l}\text { child health } \\
\text { record }\end{array}$ & $\begin{array}{l}\text { y case } \\
\text { study }\end{array}$ & $\begin{array}{l}\text { participation in } \\
\text { personal child } \\
\text { health record }\end{array}$ \\
\hline 2017 & King & 18 & Canada & $\mathrm{N}$ & $\begin{array}{l}\text { Parents } \\
\text { as } \\
\text { caregiver } \\
\text { s }\end{array}$ & $\begin{array}{l}\text { Patient } \\
\text { portal, } \\
\text { EHRs, 2- } \\
\text { way } \\
\text { messaging } \\
\text { with } \\
\text { providers }\end{array}$ & $\begin{array}{l}\text { Survey, } \\
\text { focus } \\
\text { groups, } \\
\text { interviews }\end{array}$ & $\begin{array}{l}\text { Examine the } \\
\text { use, utility \& } \\
\text { impact on } \\
\text { engagement in } \\
\text { care and } \\
\text { communication } \\
\text { of patient portal }\end{array}$ \\
\hline
\end{tabular}

Table 4: HIT types and examples related to caregivers

\begin{tabular}{|c|c|}
\hline Type of HIT related to caregivers & Examples \\
\hline $\begin{array}{l}\text { Patient portal: A secure online } \\
\text { website that gives 24-hour access to } \\
\text { personal health information with an } \\
\text { internet connection (34). }\end{array}$ & $\begin{array}{l}\text { Attitude of parents and teens toward patient portal usage } \\
\text { (24); Use, utility and impact of patient portals on } \\
\text { engagement in care an communication (25); } \\
\text { Perspectives of patients and caregivers on portal use } \\
\text { before implementation at a safety-net hospital (26); } \\
\text { Perceptions of a parent about usability \& value of } \\
\text { portals for children with chronic illness (27); }\end{array}$ \\
\hline $\begin{array}{l}\text { Telehomecare (aka telehealth): The } \\
\text { use of telecommunications } \\
\text { technologies to support long- } \\
\text { distance clinical healthcare (34). }\end{array}$ & $\begin{array}{l}\text { Experiences and attitudes of patients and caregivers } \\
\text { toward tele-homecare HIT (web portal)(31) }\end{array}$ \\
\hline $\begin{array}{l}\text { Electronic health record (EHR): A } \\
\text { record of electronic health-related } \\
\text { information that can be created, } \\
\text { managed, and consulted by } \\
\text { authorized clinicians and staff } \\
\text { across more than one healthcare } \\
\text { organization. Electronic medical } \\
\text { record is used within one healthcare } \\
\text { organization (34). }\end{array}$ & $\begin{array}{l}\text { Perceptions and experiences of parents with health } \\
\text { information \& care plan development/coordination for } \\
\text { children with tracheotomy (33) }\end{array}$ \\
\hline $\begin{array}{l}\text { e-mail: A method of } \\
\text { communication that can become } \\
\text { part of the health record( } 34)\end{array}$ & $\begin{array}{l}\text { Attitudes of pediatric caregivers toward the use of } \\
\text { electronic communication modalities in an urban } \\
\text { clinic(32) }\end{array}$ \\
\hline $\begin{array}{l}\text { Electronic personal health record } \\
\text { (EPHR): Tools that IC can use to } \\
\text { collect, track and share past and } \\
\text { current information about the } \\
\text { patient's health (34) }\end{array}$ & $\begin{array}{l}\text { Perspectives of low-income Latino parents about } \\
\text { desired characteristics of personal online pediatric } \\
\text { immunization record (28); Knowledge, interest, and } \\
\text { attitudes of patients \& caregivers towards EPHRs ( } 29 \text {, } \\
\text { 30) }\end{array}$ \\
\hline $\begin{array}{l}\text { Mobile app: Smart phone } \\
\text { applications related to collection or } \\
\text { transmission of health data (34) }\end{array}$ & $\begin{array}{l}\text { Desired features of a mobile application from the } \\
\text { perspectives of relatives to enhance elderly care-taking } \\
\text { responsibilities (13) }\end{array}$ \\
\hline
\end{tabular}




\begin{tabular}{|l|l|}
\hline $\begin{array}{l}\text { Wearables: Devices to collect data, } \\
\text { worn by the patient, mobile } \\
\text { technology that enables monitoring } \\
\text { of an individual's health status (34) }\end{array}$ & $\begin{array}{l}\text { Viewpoints of patients and caregivers about the use of } \\
\text { wearable technology in epilepsy to monitor seizures(17) }\end{array}$ \\
\hline $\begin{array}{l}\text { Internet of things: A network of } \\
\text { devices enabling collection and } \\
\text { exchange of data(43) }\end{array}$ & $\begin{array}{l}\text { Case study in Belgium considering exchange of data } \\
\text { between different professional caregivers (38);Focus } \\
\text { groups used to determine preferences of older adults for } \\
\text { using wellness tools, including use of other sources of } \\
\text { information and technology to support their health(44); } \\
\text { Internet of things is explored in healthcare (43) }\end{array}$ \\
\hline
\end{tabular}

